УДК 004:378.141.31:615.15

I. Ю. РЕВ' ЯЦЬКИЙ, канд. фарм. наук

Львівський національний медичний університет імені Данила Галиџького

ВПРОВАДЖЕННЯ АВТОМАТИЗАЦІЇ НА ОСНОВІ КОМП'ЮТЕРНИХ ТЕХНОЛОГІЙ У ПРОЦЕС КОНТРОЛЮ ЗНАНЬ ПРОВІЗОРІВ-ІНТЕРНІВ

Ключові слова: контроль знань, тестування, автоматизація процесів

\title{
I. Yu. REVYATSKYY
}

Danylo Halytsky Lviv National Medical University

IMPLEMENTATION OF AUTOMATION BASED ON COMPUTER TECHNOLOGIES

INTO PROCESS OF KNOWLEDGE CONTROLLING OF PHARMACISTS-INTERNS

Key words: knowledge controlling, tests, automation of processes

Згідно з наказом МО3 України [1] щодо впровадження ліцензійного інтегрованого іспиту «Крок 3. Фармація» (КЗФ) для провізорів-інтернів на кафедрі організації і економіки фармації, технології ліків та фармакоекономіки факультету післядипломної освіти ЛНМУ імені Данила Галицького (кафедра) розпочалося впровадження процесів організації підготовки, самопідготовки та контролю рівня знань провізорівінтернів до КЗФ [2].

На цей час в Україні не існує офіційної єдиної відкритої та загальнодоступної до використання комп'ютерної системи з банком тестових завдань (КСБТЗ), які можна використовувати у процесі підготовки провізорів-інтернів до КЗФ. Комп’ютерне тестування використовують у багатьох вищих навчальних закладах (ВН3) України $[3,4]$. Деякі ВНЗ медичного спрямування, зокрема Національний фармацевтичний університет $(\mathrm{HФаУ)} \mathrm{та} \mathrm{Тернопільський} \mathrm{державний} \mathrm{медичний} \mathrm{університет}$ імені І. Я. Горбачевського, використовують КСБТЗ локально у повсякденному навчальному процесі своїх студентів. У ЛНМУ імені Данила Галицького триває процес впровадження навчальної платформи MOODLE (Modular Object-Oriented Dynamic Learning Environment - модульне об'єктно-орієнтоване динамічне навчальне середовище) [5]. Позитивним є досвід на фармацевтичному факультеті використання студентами системи AdFarm S. A. [6].

У зв'язку із впровадженням КЗФ та збільшенням кількості годин для самостійної роботи, актуальною стала необхідність оптимізації процесу контролю рівня знань провізорів-інтернів. Тому, у відповідності до пріоритетних напрямів та програмних завдань розвитку фармацевтичного сектора [7], було вирішено у цьому процесі задіяти сучасні стандарти опрацювання цифрової інформації.

Метою роботи було оптимізувати процес контролю рівня знань провізорів-інтернів шляхом його автоматизації із використанням комп'ютерних технологій.

\section{М а т е р і а ли т а ме тоди дослідження}

Затверджені Центром тестування (ЦТ) при МО3 України (testcentr.org.ua) електронні форми подачі інформації про провізорів-інтернів, що допускаються до здачі КЗФ; тестові завдання, підготовлені викладачами ВНЗ. Використано метод узагальнення результатів попередніх досліджень про загально поширені комп'ютерні системи тестування та сучасні підходи до обміну структурованою цифровою інформацією. 


\section{Р езультати дослідження та обгов орення}

На першому етапі було проаналізовано дані літератури про наявні діючі системи тестування. Вони орієнтовані на мережевий режим із використанням персональних електронних пристроїв (ПЕП) $[8,9]$. Проте, локальне використання КСБТЗ передбачає збільшення затрат часу викладачів у процесі підготовки тестових завдань (ТЗ). Це пов'язано з необхідністю внесення у ручному режимі кожного ТЗ або у автоматичному завантаженні, що знову ж таки передбачає ручний режим підготовки кожного ТЗ у електронній формі (файлі) відповідного стандарту. Причому, для кожної КСБТЗ наявна своя унікальна форма підготовки питань для автоматичного завантаження.

На нашу думку, до основних недоліків тестування через мережу Інтернет, які наводяться у публікаціях $[9,10,11]$, можна віднести: можливість пошуку відповіді на питання через інтернет-пошукові системи чи у книгах (в т. ч. електронних 3 допомогою функції швидкого пошуку - $\mathrm{Ctrl+F);} \mathrm{залучення} \mathrm{іншої} \mathrm{особи,} \mathrm{яка} \mathrm{складатиме}$ тест сама чи допомагатиме в пошуку відповіді для його виконання; непередбаченість наявності/постійності мережевого з'єднання у момент складання тесту. Загалом, онлайн тестування дає багатопланову статистичну інформацію та не гарантує надання коректних результатів про фактичний рівень знань. Відповідно, таке тестування не має бути базовим фактором для оцінювання рівня знань підготовки провізора-інтерна.

У роботі нами також були враховані проблеми, які можуть виникати у процесі здійснення автоматизації тестування та оцінювання з його допомогою рівня знань [12].

У даному випадку термін «банк даних» (банк тестових завдань) передбачає збереження, накопичення та можливість аналізу певної інформації. Тому було вирішено обрати реляційну базу даних (РБД) як об'єкт, який відповідно до сучасних світових стандартів повністю відповідає вказаним вимогам. Центр тестування (ЦТ) вимагає подачу певної інформації про допущених до КЗФ інтернів та підготовлених викладачами ТЗ у електронних файлах, які формують у програмах Microsoft Excel та Microsoft Word [13]. Тому для зберігання цієї інформації було обрано програму Microsoft Access (MA), оскільки вона у функціональному плані повністю інтегрована iз Word та Excel. MA включає в собі РБД та систему управління базою даних (СУБД) із можливістю формування звітів. До ії переваг також відноситься мобільність - таблиці РБД зберігаються в одному файлі, а СУБД можна запустити на будьякому комп'ютері із операційною системою Windows без необхідності здійснення додаткових програмних налаштувань.

3 метою стандартизації та уніфікації процесу створення ТЗ, було взято стандарт ЦТ для форми ТЗ за основу. Нами написаний на Microsoft Visual Basic (MVB) код, який переносить інформацію із стандартизованих ЦТ таблиць у новостворену таблицю Excel. Ця таблиця $є$ адаптованою для подальшого перенесення до РБД МА. Тому кожен викладач кафедри формує тестові завдання для підсумкового контролю знань за навчальними тематичними блоками лише відповідно до стандартів ЦТ у форматі .doc. Після цього інформація об’єднується в один файл і шляхом запуску сформованих нами функцій MVB переноситься у РБД МА. Тобто, процес механічної роботи переведення працівником тестових завдань із одного формату подачі інформації в інший формат було повністю усунуто.

Проаналізувавши неавтоматизований процес проведення тестувань на кафедрі, ми виділили окремі процеси та автоматизували їх шляхом написання на MVB відповідного програмного коду, що дало змогу перекласти їх виконання на СУБД (рис. 1). 


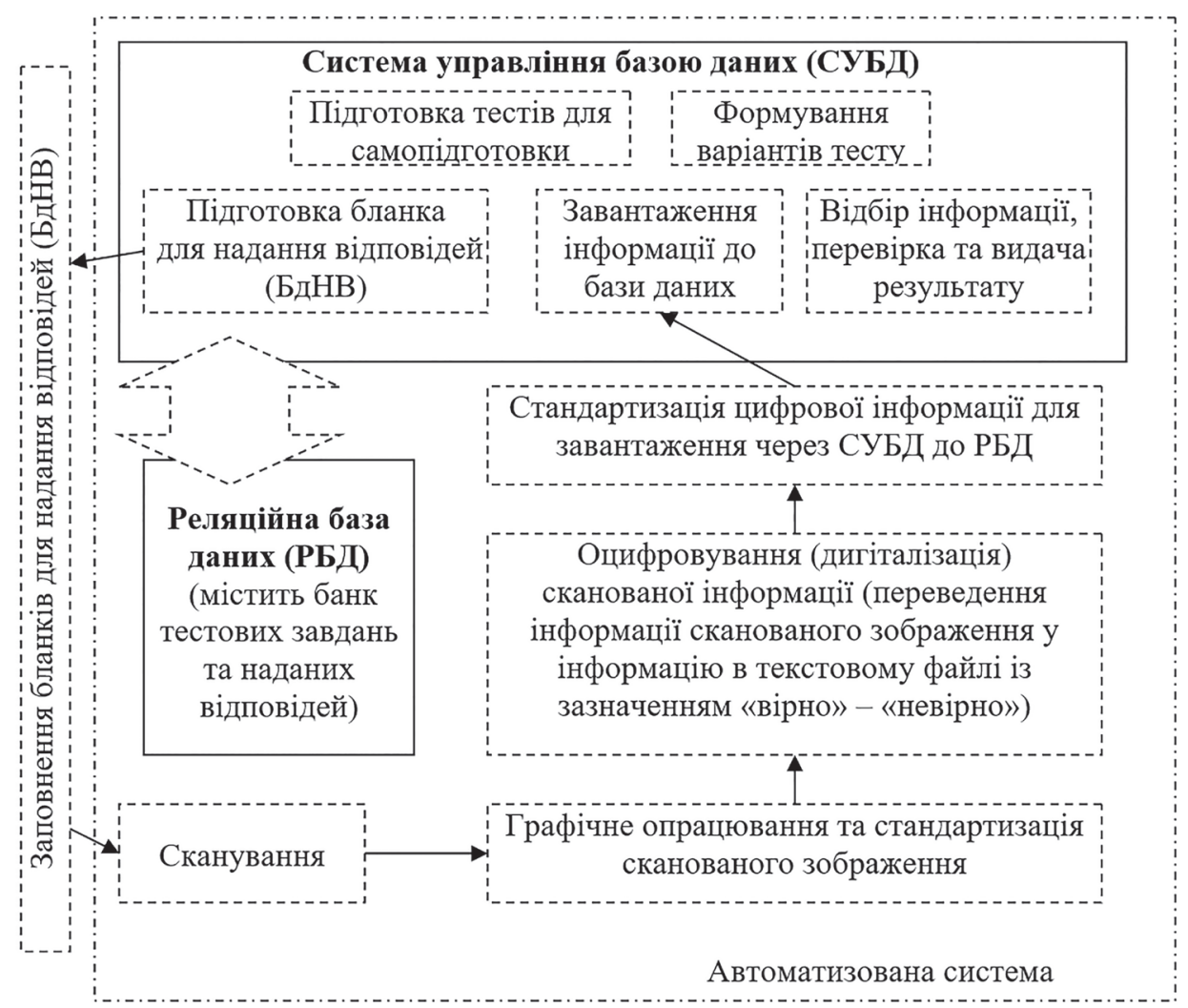

\section{Рис. 1. Блок-схема автоматизованої системи підготовки i перевірки тестових завдань}

Процеси сканування, графічного опрацювання та оцифровування сканованої інформації не були автоматизовані з допомогою СУБД, оскільки в її функціонуванні така робота не передбачена. Нами запропоновано здійснювати процес сканування у кольоровому режимі, роздільною здатністю від 300 рі та з використанням пристрою, що забезпечує автоматичну подачу нового аркуша і зберігає інформацію у форматі jpg (рис. 2,a).

Оскільки скановане зображення може мати різні параметри, нами був впроваджений процес його графічного опрацювання та стандартизації, який задає конкретну ширину, довжину та густину пікселів на дюйм. Виконання процесу було реалізовано у програмі Adobe Photoshop. При тестовому моделюванні в ручному режимі був графічно опрацьований один сканований бланк для надання відповідей (БдНВ). Всі дії, які виконували над зображенням, були послідовно записані програмою у новий набір операцій. Завдяки цьому була реалізована можливість пакетного опрацювання сканованих бланків із наданими відповідями (Файл > Автоматизація > Пакетне опрацювання) (рис. 2, $b$ ).

У процесі графічного опрацювання реалізовано наступне:

- ідентифікація заповнення здійснюється реверсним шляхом - в комірці ідентифікується іiі незаповнена площа (білий колір), що дало змогу провізорам-інтернам заповнювати БдНВ кульковою ручкою чи олівцем будь-яких кольорів;

- комірка вважається зазначеною, якщо менше 50\% її загальної площі є незаповненою.

Процес розпізнання інформації реалізовано 3 допомогою програми ABBYY FineReader 10, в якій нами сформовано нову мову, що включає лише два геометричні 
символи з кодами в системі Unicode в кодуванні UTF-8: 25A0 та 25A1 (чорний та бiлий квадрат у чорній рамці відповідно). Також створено шаблон для зон розпізнання тексту із БдНВ. Вихідна оцифрована інформація зберігається у файлі формату txt is стандартом системи ASCII у кодуванні ср1251, що відповідає кодуванню програмам Microsoft Office. Завдяки цьому відбувається іiі коректне завантаження у СУБД. У вихідному текстовому файлі порожні комірки БдНВ позначаються «?», а заповнені «»» (код ср1251: 63 та 166 відповідно, рис. 2, c). Саме ідентифікація у БдНВ кожної комірки дає змогу одержати повну статистичну інформацію про всі обрані відповіді на кожне запитання, що неможливо реалізувати у разі ідентифікації вірності відповіді на питання: «вірно» чи «хибно».
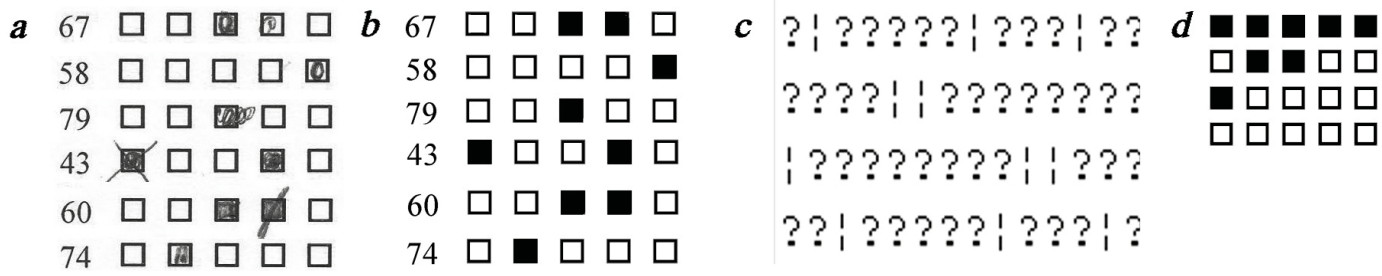

\section{Рис. 2. $\boldsymbol{a}$ - Скановані надані відповіді; $\boldsymbol{b}$ - результат графічного опрацювання наданих відповідей; $c$ - оцифровані надані відповіді у текстовому файлі; $d$ - графічне відображення id}

Процес стандартизації цифрової інформації перед завантаженням до РБД є необхідним, оскільки процес розпізнання інформації може бути реалізований із допомогою різного програмного забезпечення i, відповідно, мати після виконання різну форму подачі одержаного результату. Цей процес нами був реалізований з використанням коду MVB MA.

Процес формування БдНВ також реалізований MVB MA та створює два шаблони на листах стандартів A5 та A4 на 100 та 250 питань відповідно. Сформовані таким чином БдНВ передбачають переведення наданих провізорами-інтернами відповідей у цифрову інформацію, що дозволяє ії подальше аналітичне опрацювання.

Процес формування варіантів тесту повністю автоматизований: нами написаний код на MVB для СУБД, який на основі заданих користувачем параметрів автоматично формує варіанти для конкретного тесту, затрачаючи від кількох секунд до 1-2 хвилин на їх створення, що безпосередньо залежить від вказаних параметрів та потужностей комп’ютера, на якому ця процедура виконується.

На даному етапі функціонування СУБД для формування варіантів тестів нами закладено такі критерії:

1. Вибір тесту, для якого будуть формуватися варіанти.

2. Критерій відбору питань під час формування варіантів: довільне включення питань; жодне із питань не буде включене знову, поки не буде включене кожне.

3. Критерій відбору відповідей: спершу відбирається одна вірна відповідь, а інші - у довільній послідовності (в т. ч. й інші правильні відповіді за умови їх наявності).

4. Критерій відбору питань за тематиками: при позитивному значенні необхідно конкретно вказати, скільки питань кожної теми потрібно включити у кожний варіант тесту.

5. Критерій генерування нумерації послідовності відібраних питань для кожного варіанта: групувати питання за темами чи у довільному порядку.

6. Кількість варіантів, яку потрібно сформувати.

7. Кількість питань у варіанті.

8. Кількість відповідей для одного питання. 
Слід зазначити, що РБД, окрім самого банку питань, зберігає інформацію про питання у варіантах тестів, можливі варіанти відповідей на кожне питання у кожному варіанті та надані відповіді. Відповідно до стандартів РБД щодо надлишковості інформації, інформація про результати тестування в ній не зберігається. Вона формується автоматично СУБД при перегляді відповідного звіту шляхом перевірки правильності наданих відповідей із фактично наявними. Проте, для оптимізації швидкого доступу до перегляду результатів та процесів їх подальшого автоматизованого аналізу, результати доцільно зберігати в окремій електронній таблиці, наприклад Microsoft Excel.

Видача інформації реалізована із використанням автоматизованого формування звітів МА. Звіт видає інформацію про результат кожного провізора-інтерна за кожною тематикою, а також середній результат для кожного інтерна та для кожної тематики. Нами для кожної теми також введений медіальний результат. Порівняння середньої та медіальної величини дає змогу більш детальніше охарактеризувати рівень підготовки інтернів. У процесі подальшого використання СУБД, за необхідності, 3 метою більш точного виявлення сильних та слабших сторін знань, можливе введення інших математичних моделей аналізу інформації.

Відповідно до стандартів РБД, кожному запису автоматично присвоюється унікальний ідентифікатор (id). Отже, він присвоюється кожному інтерну та кожному тестовому завданню. Саме ці ідентифікатори зазначаються на БдНВ та дають змогу програмі ідентифікувати хто і на які питання відповідав. Оскільки розпізнання сканованого бланка проводиться у двійковій системі (зазначено-незазначено), то і відображення цих id також реалізовано у ній. Методом підбору значень $\left(2^{16}=65536\right.$, $2^{18}=262144$ тощо) була обрана величина $2^{20}=1048576$, як максимально допустиме значення id та оптимальна для графічного відображення і сприйняття на БдНВ. Для його візуалізації використовуються 20 квадратів, які розташовують прямокутником 5 x 4. Наприклад, при id = 5 будуть чорними перший та третій кубик, а інші - білими $\left(5=2^{0}+2^{2}\right)$. Графічне зображення id $=1247$ наведено на рис. $2, d$. Кожний варіант тестового завдання, крім класичного номера варіанта, містить графічне зображення id. Інтерн, отримавши буклет, переносить графічне зображення id варіанта на БдНВ та зазначає графічно свій id (id інтерна може бути зазначеним зразу під час формування СУБД БдНВ).

Для підвищення ефективності здійснення провізорами-інтернами процесу самоконтролю рівня знань на кафедрі, крім вищеописаного підходу, нами планується впровадження використання тестових контрольних завдань для самопідготовки, які розміщуються у файлі формату HTML. Структура такого документа включає: розмітку HTML (містить структуру документа, в т. ч. елементи управління); код CSS (відповідає за візуальне оформлення); блок стандарту XML (містить інформацію про тестові завдання); елементарний код JavaScript (дає змогу, враховуючи обрані користувачем параметри, довільно формувати тестові завдання та відповіді до них).

Процес складання тестів для самопідготовки передбачає автоматизоване формування блоку XML, що реалізовано у СУБД за допомогою MVB.

Основні переваги запропонованого підходу:

- використовується на будь-якому ПЕП із будь-якою операційною системою;

- відкривається з допомогою будь-якого популярного браузера;

- не потребує під'єднання до мережі;

- підвищує інтерес до розв'язання завдань, оскільки відбувається у форматі вікторини. 


\section{В и с н о в к и}

1. Завдяки впровадженню на основі застосування комп'ютерних технологій автоматизації процесу контролю рівня знань, повністю усунуто процес механічного переведення тестових завдань із однієї інформаційної структури в іншу та реалізовано одержання статистичної інформації про кожну надану відповідь.

2. Реалізовано автоматизований процес відбору із бази тестових завдань питань та відповідей на них для формування кожного варіанта відповідно до зазначених користувачем параметрів.

3. Впровадження процесу графічного опрацювання сканованих бланків із наданими відповідями забезпечило можливість провізорам-інтернам заповнювати бланки кульковою ручкою чи олівцем будь-яких кольорів.

4. Для підвищення якості самоконтролю рівня знань провізорів-інтернів запропоновано розміщення у HTML-файлах тестових завдань до винесених на самоопрацювання тем, як альтернативу проведення тестування через мережу інтернет, яке не має бути базовим фактором у разі визначення рівня їхніх підсумкових знань.

\section{С пис ок використаної літ е ратури}

1. Наказ Міністерства охорони здоров’я України № 646 від 12. 09. 2014 р. «Про затвердження Плану заходів для поліпшення якості підготовки фахівців за спеціальностями галузі знань «Фармація»»».

2. Лелека М. В., Заліська О. М. Забезпечення підвищення якості освіти через ліцензійний інтегрований іспит «Крок 3. Фармація» для провізорів-інтернів / Фармація XXI століття: тенденції та перспективи: Мат. VIII нац. з'їзду фармацевтів України. Харків: НФаУ, 2016. - Т. 2. - С. 253.

3. Родіонова А. О., Самойлова С. Л. Комп’ютерне тестування як метод кількісного педагогічного вимірювання // Проблеми інженерно-педагогічної освіти. - 2013. № 40-41. - С. 140-145.

4. Волкова С. О. Сучасний стан та проблеми комп'ютерного тестування знань студентів [Електронний ресурс]. - Режим доступу: http://www.chito.in.ua/suchasnijstan-ta-problemi-komp--yuternogo-testuvannya-znane-s.html

5. Триус Ю. В., Герасименко I. В., Франчук В. М. Система електронного навчання BНЗ на базі MOODLE: Метод. посібник / За ред. Ю. В. Триуса. - Черкаси, 2012. - 220 с.

6. Горілик А. В., Терещук С. І., Громовик Б. П. Створення системи комп’ютерної підтримки вивчення дисципліни «Організація та економіка фармації» // Управління, економіка та забезпечення якості в фармації. - 2008. - Т. 1, № 2. - С. 31-37.

7. «Про затвердження Концепції розвитку фармацевтичного сектору галузі охорони здоров’я України на 2011-2020 роки»: Наказ МОЗ України від 13. 09. 2010 р. № 769 .

8. Ананченко И. В. Классификация компьютерных систем тестирования знаний учащихся // Междунар. журн. экспериментального образования. - 2016. - № 4-2. C. 210-213.

9. Басюк Т. М., Павелко В. В. Аналіз та класифікація програмних засобів тестування знань // Вісн. нац. ун-ту «Львівська політехніка». - 2010. - № 686. - С. 213-2017.

10. Криворучко A. В. Аналіз тестових програмних засобів online. Інтернет тестування: переваги та недоліки // Інформаційно-комунікаційні технології в освіті. - 2015. - № 2 [Електронний ресурс]. - Режим доступу: http://e-journals.npu.edu.ua/ index.php/ikt/article/view/76/pdf

11. Онлайн-освіта: як боротися із шахрайством студентів? / Електронний портал osvita.ua [Електронний ресурс]. - Режим доступу: http://osvita.ua/vnz/high_ school/32317/ 
12. Коноваленко O. С., Брусенцеев В. О. Проблема автоматизованого тестування та оцінювання знань // Системи обробки інформації. - 2012. - Вип. 2, № 100. C. 301-305.

13. «Центр тестування» [Електронний ресурс]. - Режим доступу: http://testcentr. org.ua

Надійшла до редакції 10 лютого 2017 року.

\section{И. Ю. Ревяцкий}

Львовский национальный медиџинский университет имени Данила Галиџкого

ВНЕДРЕНИЕ АВТОМАТИЗАЦИИ НА ОСНОВЕ КОМПЬЮТЕРНЫХ ТЕХНОЛОГИЙ В ПРОЦЕСС КОНТРОЛЯ ЗНАНИЙ ПРОВИЗОРОВ-ИНТЕРНОВ

Ключевые слова: контроль знаний, тестирование, автоматизация процессов А Н Н О Т А ЦИ Я

В связи с внедрением «Крок 3. Фармация» и увеличением количества часов для самостоятельной работы, актуальной стала необходимость оптимизации процесса контроля уровня знаний провизоров-интернов. В соответствии с приоритетными направлениями и программными задачами развития фармацевтического сектора в Украине, мы решили задействовать в этом процессе современные стандарты обработки цифровой информации. Поэтому целью работы было оптимизировать процесс контроля уровня знаний путем его автоматизации с использованием компьютерных технологий.

Использован метод обобщения результатов предыдущих исследований об общераспространенных компьютерных системах тестирования и современных подходах к обмену структурированной цифровой информацией. Объектами исследования также были утвержденные Центром тестирования при МЗ Украины (testcentr.org. ua) электронные формы подачи информации о провизорах-интернах, которые допускаются к сдаче «Крок 3 », и о тестовых заданиях, подготавливаемых преподавателями ВУЗов.

На основе анализа неавтоматизированного хода проведения тестирований на кафедре нами были выделены его отдельные процессы. Путем написания программного кода в системе управления базами данных была реализована автоматизация следующих процессов: подготовка тестов для самоподготовки; формирование вариантов теста; подготовка бланка для предоставления ответов; стандартизация цифровой информации для загрузки; загрузка информации в базу данных; проверка и выдача результата. Другие процессы (сканирование; графическая обработка и стандартизация сканируемого изображения; оцифровка сканированной информации) были автоматизированы с использованием других цифровых технологий.

В результате проведенной работы был полностью устранен процесс механического перевода тестовых заданий с одной информационной структуры в другую и реализовано получение статистической информации о каждом предоставленном провизором-интерном ответе. Была реализована возможность автоматического формирования вариантов тестов в соответствии с указанными пользователем параметрами. За счет внедрения процесса графической обработки сканированных бланков с предоставленными ответами была обеспечена возможность их заполнения шариковой ручкой или карандашом любых цветов. Также нами предложено размещение тестовых заданий в файлах формата HTML с целью повышения качества самоконтроля уровня знаний провизоров-интернов. 
I. Yu. Revyatskyy

Danylo Halytsky Lviv National Medical University

IMPLEMENTATION OF AUTOMATION BASED ON COMPUTER TECHNOLOGIES

INTO PROCESS OF KNOWLEDGE CONTROLLING OF PHARMACISTS-INTERNS

Key words: knowledge controlling, tests, automation of processes

A B S T R A C T

Optimization of the process of knowledge controlling of pharmacists-interns has become a current issue due to implementation of «Krok 3. Pharmacy» and increase in the number of hours for individual work. According to priority directions and program tasks for the development of pharmaceutical sector in Ukraine, we decided to involve contemporary standards for digital processing of information. Thus, the aim of the work was to optimize the process of controlling the level of knowledge by means of its optimization using computer technologies.

Generalization of the results of previous investigations on common computer testing systems and current approaches to digital information exchange was used. Data in electronic forms approved by Testing center of Ministry of Health of Ukraine (testcentr.org.ua) were also used as research objects. The data include information about pharmacists-interns who are allowed to pass Krok 3 and tests that are prepared by university tutors.

Based on analysis of non-automated conduction of testing at the department, we have pointed out certain processes. Writing a program code in the system of database management, automation of the following processes was implemented: formation of test options; preparation of a form for writing answers; standardization of digital information for downloading; downloading of information to database; checking and presenting results. Other processes (scanning, graphic processing and standardization of scanned imaging; digital record of scanned information) were automated applying other digital technologies.

As a result of conducted work, the process of mechanical transformation of test tasks from one information structure into the other one has been completely eliminated; obtaining of statistic information about each answer provided by a pharmacist-intern has been implemented. Possibility of automatic formation of test options according to the user's suggested parameters became possible. Due to implementation of graphic processing of scanned forms with completed answers, possibility of their filling with a pen or a pencil of any color was provided. We also suggested storage of test tasks in HTML format in order to improve self-control of knowledge level of pharmacists-interns.

Електронна адреса для листування завторами: iwan.revyatskyy@i.ua 